\title{
Innovation and Practice of Computer Hardware Curriculum System in Application-oriented Undergraduate Education
}

\author{
Fang LI, Yue-ying WU and Sheng-ju SANG \\ School of Information Science and Technology \\ Taishan University \\ Taian Shandong, China, 271000 \\ Corresponding author: sang1108@163.com
}

\author{
Yue-ying WU \\ School of Information Science and Technology \\ Qingdao University of Science and Technology \\ Qingdao, Shandong, China, 266061 \\ wyy7758525@126.com
}

\begin{abstract}
This paper demonstrates a thoroughly innovative research on computer hardware curriculum including the goal of it, the hierarchy and contents of teaching, the knowledge base and communication methods. The curriculum practice, to some appropriate extent, brings together 'topical case studies', 'class projects', and 'study and engineering work in industry' activities throughout the teaching progress. It covers the core requirements from society, and emphasizes cultivating the creative thinking, problem-solving abilities from a real engineering perspective. This research provides a broad background in computer engineering concepts and enhanced teaching practice that could meet requirements from a wide range of industries and organizations.
\end{abstract}

Keywords—application-oriented undergraduate education; computer hardware; curriculum system.

\section{INTRODUCTION}

Computer disciplines are categorized into five curricular areas by IEEE-CS/ACM. These areas include: computer science, computer engineering, software engineering, information systems and information technology [1-3]. With the tremendous development of computer technology, more and more research and engineering areas are boosted by computer. The original course hierarchy is not suitable for the goals of all colleges [4-6]. Foreign universities, like MIT, UC Berkley, Stanford, MCUs have setup computer curriculum with special features $[7,8]$. The Computer Science and Technology Teaching Steering Committee of the Ministry of Education of China proposes the direction of computer disciplinary development with the spirit of "classified educational specification" and encourages universities providing various types (research, engineering, application) of curriculum plans[9] based on both social exceptions and available resources. Tsinghua University, Zhejiang University, Nanjing University, Peking University of Aeronautics and Astronautics have made some progress on such kind of research and brought forward practice plans on curriculum, contents and laboratories [10-11].

\section{CURRICULUM IN UNDERGRADUATE COMPUTER HARDWARE}

The goal focuses on computer applications to meet real engineering activities which not only include broad theories, but problem-solving techniques in engineering. According to this goal, this paper optimizes the original courses 'Computer Organization', 'Principle of Mini-computer', 'Principle of MCU', and 'Computer Architecture' in undergraduate phase; setup both the teaching arrangement and curriculum for computer hardware knowledge base. The curriculum plan is shown in Fig. 1.

\section{KNOWLEDGE STRUCTURE OF COMPUTER HARDWARE COURSE}

There exist connections among these standalone computer hardware courses. Current teaching practice often focuses on the main chapters and specialties of each course while omitting the connections with other courses, which block the consistency of knowledge acquisition for students. Meanwhile, for application-oriented undergraduate students, chipset related knowledge is too profound to grasp and not easy to be applied directly. The optimization of this curriculum is exemplified with below changes in the course of 'Principle of Computer Organization' and 'Mini-computer Interfaces technology'.

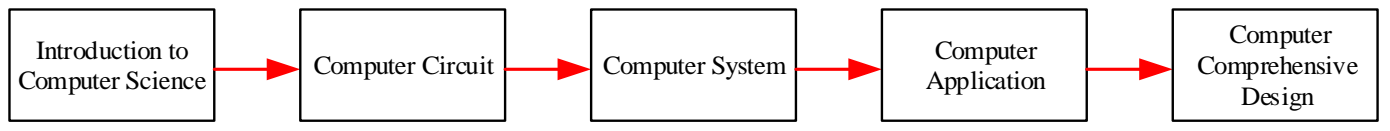

Fig. 1. Computer hardware curriculum system plan 
TABLE I. I LCTURE HOUR'S ALLOCATION OF COMPUTER HARDWARE COURSE

\begin{tabular}{|c|c|c|c|c|c|c|}
\hline \multirow{2}{*}{ Courses } & \multirow{2}{*}{ Type } & \multirow{2}{*}{ Credit } & \multicolumn{3}{|c|}{ Class hours } & \multirow{2}{*}{ Semester } \\
\hline & & & Total & Theory & Experiment & \\
\hline Introduction to Computer Science & Compulsory & 5 & 80 & 44 & 36 & 1 \\
\hline Computer Circuit & Compulsory & 5 & 96 & 78 & 18 & 2 \\
\hline Computer system architecture (1) & Compulsory & 4 & 72 & 54 & 18 & 3 \\
\hline Computer system architecture (2) & Compulsory & 4 & 72 & 54 & 18 & 4 \\
\hline Computer network & Optional & 3 & 54 & 36 & 18 & 5 \\
\hline Principle of MCU & Optional & 3 & 54 & 36 & 18 & 5 \\
\hline Computer system design & Optional & 3 & 54 & 36 & 18 & 6 \\
\hline Embedded system & Optional & 3 & 54 & 42 & 12 & 6 \\
\hline Internet of things technology & Optional & 3 & 54 & 42 & 12 & 6 \\
\hline Computer Comprehensive Design & Compulsory & 4 & 72 & 20 & 50 & 7 \\
\hline
\end{tabular}

Lecture hours allocation is shown in table 1.

In the course of 'Principle of Computer Organization', there are detailed explanations on microcode working principles, structures, design of logics inside controllers and accumulators. These are basic knowledge for processor designer and researchers, but for computer applications, who cares at most about processor features and programmable registers, the internal structure details could be seen as a 'black box'.

And in the teaching practice of 'Mini-computer Interface Technologies', the $8086 / 8088$ assembly programming could be simplified; the legacy parallel interface chips learning could be shorten; for important concepts like DMA, just focuses on its principles; and for other chipset features, only a brief introduction. These changes impacts little on the undergraduates' ability preparations as the legacy parallel chips and 8086/8088 assembly are almost unavailable in real applications. We could put the bus, memory related contents into the 8051-chip sub-system context; not only for its simplicity, but straight forward and easy to understand and grasp the spirits.

\section{CONTENTS OF TEACHING IN COMPUTER HARDWARE CURRICULUM}

Some contents appear in multiple courses in computer hardware and teachers usually explain them from the perspective of each course. This forms the fact that for one knowledge unit, many teachers mentioned, but no one gives a clear description, which makes students feel dull and negates learning interests. For example, 'data checksum' appears in the courses of 'Principle of Computer Organization', 'Computer Architectures', 'Assembly Programming' and 'Computer Networks'. The depths of contents for this concept are almost the same in these courses except that the 'Assembly Programming' course goes further into the programming. Another example is the 'interrupt', also appear in multiple courses, but students are often have no idea when they try to use the interrupt mechanism in their programs. So this paper proposes to integrate computer hardware curriculum contents and re-contracture the courses of 'Computer Hardware Basics', 'Computer Architecture' for application-oriented undergraduate educations.

To meet various personal interests of students and the profession realm, the undergraduate computer hardware courses should also include 'Principle of MCU', 'Embedded System Design', 'Computer Organization', 'Computer Network', 'Internet of things technology', etc. These courses could enhance students' cognation of computer system and setup a better foundation for future career development planning.

\section{TEACHING METHODS}

The inert interest is the key factor of achieving the expected learning outcome. Some popular ideas among students like "hardware is difficult to learn", "hardware is useless" were generated with comprehensive factors. Teaching experiences from our research group show that the complex details, difference in mechanism with human being behaviors and abstract instructions lead to those ideas. So in our teaching practice, "learning centric and preparing for all-round capability" is our primary goal to override traditional teaching methods.

\section{A. Class Lectures}

In teaching practice, we set up the goal of "learning centric and preparing for all-round capability" and the criteria of "Whether or not this could seize hearts of students". Heuristic teaching methods like "explains profound knowledge with simple words", 
"highlights the trunk", "makes difficult items completely known", "induce self-learning" are applied to get better outcomes of learning.

\section{B. Laboratories}

For hardware courses, students should integrate theoretical knowledge with the actual computer, integrated circuit chip, and carry out the actual design and implementation, in order to master and draw inferences from known contents. Because of various restrictions, the students use their theories to solve the actual design problems of hardware, which is weak and confined to limited experimental practices. Because of students' learning ability is uneven, computer hardware that is "visible" and "materialized" is treated by many students to be an "abstract" theory. This leads to the bad learning outcome and the fear on computer hardware, which makes the computer hardware knowledge a bottleneck in the students' learning curve'.

"Task driven" is an experimental mode of inquiry teaching. Its remarkable feature is that both teaching and learning are based on several tasks to prepare students' ability of self-learning and problems analysis and solving. The combination of "task driven" spirit and computer hardware teaching, constructs a new research direction on teaching content, the theoretical knowledge to be taught and practical skills are decomposed into several experimental subjects with clear application scenarios according to the principle of "from the shallower to the deeper", and stipulate students to complete these subjects independently within the specified time, so as to achieve the teaching goal.

Based on the key discipline" computer application technology" in the 11th and the 12th Five-Year plans of Shandong province, and the experimental demonstration center of Shandong province - "basic computer laboratory center", by adopting "MCU laboratory ","the principle of the mini-computer laboratory", "embedded system laboratory","IoT Laboratory " and "automatic control laboratory" as the experimental platform and taking the vertical and horizontal research projects and the College scientific innovation project" as an opportunity, guide the students to actively participate in research projects, stimulating students' interest in learning and cultivating students' practical ability, in order to improve the level of scientific research and innovation, and form a set of perfect practice system.

\section{Encourage Bilingual Teaching}

The implementation of bilingual teaching not only enables students to expand their knowledge, but also enables students to get to know the latest and best achievements in the world in terms of educational philosophy and preparing models. Based on the bilingual teaching, characteristics like hard-working, modest in domestic students and those wide-interested in, wide field of vision, courage, risk-taking in foreign students could be combined; the rigor and integrity of the traditional domestic knowledge system and the pay attention to master the inner spirit and development of knowledge abroad could be combined; the domestic emphasize on theoretical knowledge of students and foreign students emphasize self-reliance and pioneering spirit could be combined; the domestic realistic style and foreign romantic style in education could be combined; the domestic "learning more than thinking" and the "thinking more than learning" abroad could be combined, in educational philosophy, teaching methods, preparation mode to achieve a breakthrough.

\section{SUMMARY}

This paper proposes optimizations of computer hardware courses and set up a new curriculum structure aiming at applicationoriented undergraduate educations. The new 'Computer Hardware Basics' and 'Computer Architectures' simplify some complex concepts and give students a easy-to-understand whole picture of computer, also with new technologies in this area. Meanwhile, according to students' interest and professional realms, the elective courses like 'Principle of MCU', "Embedded System Design", etc. are setup. In teaching practice, we set up the goal of "learning centric and preparing for all-round capability" and the criteria of "Whether or not this could seize hearts of students". Heuristic teaching methods like "explains profound knowledge with simple words", "highlights the trunk", "makes difficult items completely known", "induce self-learning" are applied to get better outcomes of learning. This innovation could be used extensively and it could bring enhanced cognitions of computer system, more practice in system integration and application and better preparation for qualified professionals that could adapt to emerging industries.

\section{ACKNOWLEDGEMENT}

The Research was partially supported by "The reform and Practice Research of computer hardware basic course system of Applied Undergraduate Course" of the Research project on teaching reform of Shandong Provincial Education Department, China (NO. LU JIAO GAO WEN 2015-02), the science and technology development fund of Tai' an (No. 20133011, 201320629 and 2016GX0004), and the Foundation provided by Taishan University (no.Y-01-2013010). The authors also thank the associate editor and the anonymous reviewers for their valuable comments.

\section{REFERENCES}

[1] ACM/AIS/IEEE-CS, Computing Curricula 2005[OL/S], http://www.acm.org/education/curric_vols/CC2005- March 06 Final.pdf.

[2] MIT. Computer Systems Engineering [EB/OL].Spring 2014.http://web.mit.edu /6.33/www/ index.shtml/. 
[3] UC Berkeley. CS courses information \&scheduling [EB/OL]. (2012-08-27). http://www.eecs.berkeley.edu/ Scheduling/CS/.

[4] Stanford University. Computer organization and systems. [EB/OL].Spring 2012. http://www.stanford.edu/class/cs107/.

[5] CMU. Introduction to computer systems. [EB/OL]. Fall2014.http://www.cs.cmu. edu/ 213/.

[6] Nanjing University teaching system, [EB/OL].http://software.nju.edu.cn/ index.php option= com_content \& view=article\&id= 146\&Itemid= 4/.(In Chinese)

[7] TANG Zhiqiang, ZHU Zicong. Reform and innovation of digital logic curriculum for coputer sciece major, Computer Engineering \& science, 2014, (S2):159-161.

[8] SANG Sheng-ju \& SHEN Ding. Principle and application of microcontroller. Beijing: China Railway Publishing House, 2010:2-10. (In Chinese)

[9] Zhang L B, Zhang F, Luo T J. Knowledge structure evolution and evaluation method in computer science. Journal of University of Chinese Academy of Sciences, 2016, 33( 6) : 844-850. (In Chinese)

[10] [10] FENG Weijian. Study on the reform of computer major course system in university. Journal of Hunan City University, 2016, (03): 265-266. (In Chinese) 